\title{
BMJ Open Factors influencing career intentions on completion of general practice vocational training in England: a cross- sectional study
}

\author{
Jeremy Dale, Rachel Russell, Emma Scott, Katherine Owen
}

To cite: Dale J, Russell R, Scott $\mathrm{E}$, et al. Factors influencing career intentions on completion of general practice vocational training in England: a cross-sectional study. BMJ Open 2017;7:e017143. doi:10.1136/ bmjopen-2017-017143

- Prepublication history for this paper is available online. To view these files, please visit the journal online (http://dx.doi. org/10.1136/bmjopen-2017017143).

Received 4 April 2017 Revised 29 May 2017 Accepted 26 June 2017

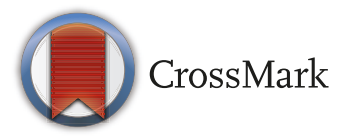

University of Warwick, Warwick Medical School, Coventry, UK

Correspondence to

Professor Jeremy Dale;

jeremy.dale@warwick.ac.uk

\section{ABSTRACT}

Objectives General practice is experiencing a growing crisis with the numbers of doctors who are training and then entering the profession in the UK failing to keep pace with workforce needs. This study investigated the immediate to medium term career intentions of those who are about to become general practitioners (GPs) and the factors that are influencing career plans.

Design Online questionnaire survey, with quantitative answers analysed using descriptive statistics and free text data analysed using a thematic framework approach. Setting and participants Doctors approaching the end of 3-year GP vocational training in the West Midlands, England.

Results 178 (57.2\%) doctors completed the survey. Most participants planned to work as salaried GPs or locums rather than entering a general practice partnership for at least the first 5 years post-completion of training; others failed to express a career plan or planned to leave general practice completely or work overseas. Many were interested in developing portfolio careers. The quality of general practice experience across undergraduate, foundation and vocational training were reported as influencing personal career plans, and in particular perceptions about workload pressure and morale within the training practices in which they had been placed. Experience of a poor work-life balance as a trainee had a negative effect on career intentions, as did negative perceptions about how general practice is portrayed by politicians and the media.

Conclusion This study describes a number of potentially modifiable factors related to training programmes that are detrimentally influencing the career plans of newly trained GPs. In addition, there are sociodemographic factors, such as age, gender and having children, which are also influencing career plans and so need to be accommodated. With ever-increasing workload in general practice, there is an urgent need to understand and where possible address these issues at national and local level.

\section{INTRODUCTION}

In the face of increasing practice workload and declining recruitment, retention and morale in the general practice workforce, there are major concerns about the capacity of general practice to safely and
Strengths and limitations of this study

- The study addresses a key workforce challenge facing general practice: the need to attract newly qualified doctors to train and enter the profession.

- The survey was limited to a single English region and the response rate, although reasonable for this type of questionnaire study, means that the findings should be interpreted cautiously.

- The mix of open and closed questions allowed identification of ambivalence about the current state of general practice in England, with factors influencing career plans including experience of undergraduate, foundation year and vocational training, practice workload, work-life balance, practice morale and media and political commentary.

- The findings confirm and add depth to those reported in other recent studies investigating recruitment to the general practice workforce.

effectively meet patients' needs. ${ }^{1-6}$ National policy has set a target for half of UK medical school graduates to enter general practice training, ${ }^{7}$ but recruitment continues to fall short with $10 \%$ of general practice training places in England unfilled in $2016 .{ }^{8}$ The attractiveness to recently qualified doctors of general practice as a career is at an all-time low, ${ }^{9}$ with workload, uncertainty about the future of general practice and lack of respect for general practitioners (GPs) identified as important factors. ${ }^{10}$

A recent systematic review has identified intrinsic, institutional and professional factors influencing recruitment to general practice. ${ }^{11}$ Factors that particularly attract doctors towards general practice vocational training in the UK include flexibility of working arrangements, reduced out of hours commitment and work-life balance. ${ }^{2} 1213$ However, many early career GPs appear to regret their career choice and a recent study suggests that work-life balance is no longer perceived as an attractor to general practice. ${ }^{12}$ 
A recent national study of 322 GPs who had completed specialist training within the previous 5 years (first five GPs) reported that $41 \%$ would not have chosen to become a doctor on reflection, 34\% regretted having chosen general practice as their specialty and $36 \%$ were considering moving abroad to work. ${ }^{14}$ Sixty-four per cent disagreed with the statement that 'the future of General Practice looks bright', with reasons given including government policies, patient demands, unsustainable workload and low morale. ${ }^{14}$ However, these findings need to be interpreted cautiously as recruitment was mainly through social media platforms and bulletins, and hence representativeness is questionable.

The current study was undertaken to explore the immediate to medium term career intentions of those who are completing GP vocational training, and the factors that have influenced their plans to identify ways of improving the future training, recruitment and retention of GPs. It was also designed to provide baseline data for a longitudinal study investigating the employment and career plans of doctors during the first five years' post-completion of training; this will involve self-completed questionnaires administered at regular intervals.

\section{METHOD}

\section{Population and setting}

Participation was limited to GP trainees employed in the region within which the study was commissioned and hence no formal sample size calculation was undertaken. The West Midlands is one of the largest regions in England with about 300 GP trainees completing specialist training each year. All (311) GP trainees in the West Midlands who were within 3 months of certificate of completion of training (CCT) in 2015 were invited by email to complete an online questionnaire. The emails were sent from Health Education England (the organisation responsible for GP vocational training) with reminders sent after 2 and 4 weeks. To maximise participation, the study was also promoted at the leavers' conference and at several local vocational training sessions across the area. In addition, a $£ 15$ voucher was offered as an incentive to participation in the study.

\section{Instrument}

The questionnaire was presented online, with a paper version available for those who preferred. It comprised of questions covering: undergraduate experience (initial career choice, exposure to general practice), specialist training (reasons for choice, experience, satisfaction), career intentions (type of working, relocation, career break) and demographics (age, gender, ethnicity, foundation school, location of training). Most questions involved Likert scales with free text space for expanding on answers. No personally identifiable information was requested.

The survey was piloted with a group of GPs to ensure clarity and that it was simple to navigate and complete.

\section{Data analysis}

Participant demographics were compared with those of all trainees who were eligible to participate (data provided by Health Education West Midlands) using $\chi^{2}$ tests to determine the representativeness of the sample; adjusted standardised residuals were calculated to identify the source of any differences.

Relationships between variables using interval rating scales were explored using Pearson's product moment correlation coefficient. $\chi^{2}$ tests were undertaken to explore associations within the categorical data. Logistic regression was considered, but multicollinearity of predictor variables meant that the assumption of independence was violated. All statistical analyses were undertaken using IBM SPSS Statistics V.23, and p values of less than 0.05 were considered to be significant unless otherwise stated.

Qualitative data from the free text data provided by participants to expand on their answers were analysed using a framework approach. ${ }^{15}$ The data were collated and, after familiarisation, two researchers coded all the data using both a deductive and inductive method to allow for exploration of unexpected findings coupled with predetermined themes, so ensuring important aspects were not missed. Any differences in interpretation were discussed, reviewed and resolved, involving when required other members of the research team. NVivo software V.10 was used to interrogate the data and facilitate a framework matrix. Qualitative quotes were identified to illustrate each theme, including the range of views represented in the data.

The quotes presented are coded in accordance to gender ( $\mathrm{F}$-female $\mathrm{M}$-male $\mathrm{U}$ - unknown), age range (1: 25-34 years, 2: 35-44 years, 3: 45-54 years, U: unknown) and participant number.

\section{Ethics}

Ethical approval was provided by the University of Warwick's Biomedical Sciences Research Ethics Committee. Consent to participate in the study was sought at the start of the questionnaire.

\section{RESULTS \\ Characteristics and career plans of the participants}

In total, 178 individuals consented to participate and 169 completed the survey, a response rate of $57.2 \%$ and completion rate of $94.9 \%$. The nine participants who failed to complete the survey each answered less than five $(10 \%)$ questions; none of them provided any free text comments.

Those who provided demographic data $(n=122 ; 68.5 \%$ of respondents) were predominately female $(n=77$; $63.1 \%)$, aged $25-34$ years $(\mathrm{n}=79 ; 69.9 \%)$ and married $(\mathrm{n}=73 ; 60.8 \%)$. Some had children $(\mathrm{n}=54 ; 44.6 \%)$ and a small number had other caring responsibilities $(n=5$; $4.2 \%)$. The majority identified as White/White-British/ White Irish $(\mathrm{n}=65 ; 53.3 \%)$ or Asian/Asian British $(\mathrm{n}=41$; $34.5 \%)$. Birmingham was the most frequently stated 
Table 1 Anticipated career plans in 6 months, 3years and 5 years

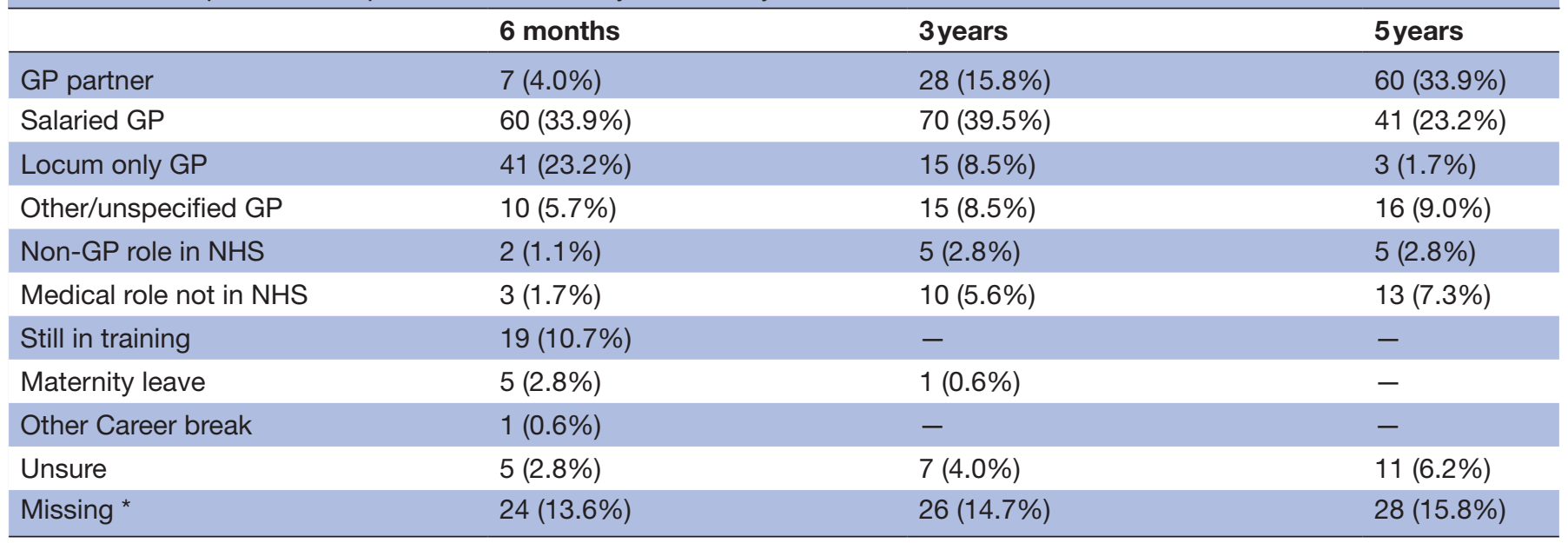

*Includes uninterpretable responses, for example, 'Win the lottery', 'Hand-holding', 'Find a niche'.

GP, general practitioner; NHS, National Health Service.

institution for undergraduate medical studies $(\mathrm{n}=38$; $31.9 \%)$, followed by Warwick $(\mathrm{n}=11 ; 9.2 \%)$ and 20 (16.4\%) listed overseas universities. None of the participants who failed to complete the survey provided any demographic information and only one answered the question regarding career intentions, expressing an intention to stay in general practice.

There was no difference in age $\left(\chi^{2}=3.35, \mathrm{p}=0.19\right)$ or gender $\left(\chi^{2}=0.84, \mathrm{p}=0.36\right)$ between those eligible to participate in the study and those for whom demographic data were known, but the reported ethnicity of the survey participants indicated an over-representation of white participants with $53.3 \%$ of respondents identifying as white, compared with $37.6 \%$ of the eligible population $\left(\chi^{2}=12.71, \mathrm{p}=0.026\right)$.

Participants' career plans are shown in table 1. Just over half $(\mathrm{n}=111 ; 62.8 \%$ stated that they expected to be working in 6 months as a salaried, locum or other non-principal National Health Service (NHS) GP, reducing slightly $(\mathrm{n}=100 ; 56.5 \%)$ for 3 years' time. For 5 years' time, this dropped to a third $(\mathrm{n}=60 ; 33.9 \%)$. The expectation of entering a GP partnership grew from $7(4.0 \%)$ at 6 months, to $28(15.8 \%)$ at 3 years and 60 $(33.9 \%)$ at 5 years. A sizeable proportion of individuals did not describe their future career plans, perhaps expressing ambiguity about career direction.

In relation to short-term career plans, participants with children were more likely to anticipate that in 6 months they would be working as a locum $(47.2 \%$ compared with $23.2 \%$ of those without children), whereas those without children were more likely to anticipate being a salaried GP $\left(69.6 \%\right.$ compared with $44.4 \%$ with children; $\chi^{2}=6.242$, $\mathrm{p}=0.044)$.

Regarding longer term career goals, age and gender were associated with career plans at 3 years: women were more likely to be planning to be in a salaried role $(69.7 \%$ compared with $35.7 \%$ men), whereas men were more likely to be aiming for a partnership $(42.9 \%$ compared with $21.2 \%$ women) or locum role (21.4\% compared with $9.1 \%$ women; $\left.\chi^{2}=22.69, \mathrm{p}<0.001\right)$. Similarly, those aged $35-44$ years were more likely to express the intention to become partners $(63.2 \%$ compared with $19.0 \%$ younger participants), whereas those who were younger were more likely to be aiming for a salaried post $(71.4 \%$ compared with $10.5 \%$ older participants; $\left.\chi^{2}=9.49, \mathrm{p}<0.01\right)$.

\section{Experience of vocational training}

As shown in table 2, most respondents felt that their overall experience of GP training, and particularly their clinical placements, had successfully prepared them for their future career, although there was a lower level of satisfaction expressed for the training sessions organised by the vocational training scheme. However, respondents were more divided about the experience of workload, work-life balance and morale in the practice in which they had trained.

\section{Key factors influencing immediate to medium term career plans}

Four themes encompassed the factors that were influencing respondents' career plans for the following 5 years. These were the experience of: general practice within undergraduate and vocational training; general practice workload; and work-life balance; practice morale and media and political commentary.

\section{Undergraduate experience and vocational training}

Participants who had experienced a positive general practice placement during undergraduate training highlighted this as having been an important influence on their career choice.

"I had a brilliant GP placement as an undergraduate with GPs who were excited and passionate about their careers and I got to see first-hand how good GPs could be invaluable to patients. I wanted to have as much impact on patient lives 
Table 2 Responses to statements regarding experience of GP undergraduate, foundation year and vocational training

\begin{tabular}{lllll} 
Questionnaire item & Agree/Strongly agree & Neutral & $\begin{array}{l}\text { Disagree/Strongly } \\
\text { disagree }\end{array}$ & Not answered \\
\hline $\begin{array}{l}\text { My undergraduate experience promoted } \\
\text { general practice as a positive career } \\
\text { choice. }\end{array}$ & $74(41.6 \%)$ & $57(32.0 \%)$ & $40(22.5 \%)$ & $7(3.9 \%)$ \\
$\begin{array}{l}\text { General practice was my first choice } \\
\begin{array}{l}\text { career on completing undergraduate } \\
\text { training. }\end{array}\end{array}$ & $70(39.5 \%)$ & $26(14.7 \%)$ & $72(40.7 \%)$ & $9(5.1 \%)$
\end{tabular}

\begin{tabular}{|c|c|c|c|c|}
\hline $\begin{array}{l}\text { I had a general practice placement during } \\
\text { F2 and this influenced my decision in a } \\
\text { positive way to pursue a career in general } \\
\text { practice. }{ }^{*}\end{array}$ & $69(39.0 \%)$ & $10(5.6 \%)$ & $14(7.9 \%)$ & $\begin{array}{l}10(5.6 \%) \\
\text { answered neither } \\
\text { of these two } \\
\text { questions }\end{array}$ \\
\hline $\begin{array}{l}\text { I did not have a general practice } \\
\text { placement during F2 but I would have } \\
\text { liked to have had one.* }\end{array}$ & $49(27.7 \%)$ & $15(8.5 \%)$ & $10(5.6 \%)$ & \\
\hline $\begin{array}{l}\text { General practice training has prepared } \\
\text { me to apply for the career choices I am } \\
\text { considering. }\end{array}$ & $131(73.6 \%)$ & $23(12.9 \%)$ & $13(7.3 \%)$ & $11(6.2 \%)$ \\
\hline $\begin{array}{l}\text { My ST3 practice placement(s) prepared } \\
\text { me for life as a GP. }\end{array}$ & $140(78.7 \%)$ & $18(10.1 \%)$ & $9(5.1 \%)$ & $11(6.2 \%)$ \\
\hline $\begin{array}{l}\text { My weekly GP vocational training scheme } \\
\text { sessions prepared me for general practice. }\end{array}$ & $74(41.6 \%)$ & $36(20.2 \%)$ & $57(32.0 \%)$ & $11(6.2 \%)$ \\
\hline $\begin{array}{l}\text { The workload in my ST } 3 \text { training practice } \\
\text { has influenced my future career intentions. }\end{array}$ & $122(68.5 \%)$ & $27(15.2 \%)$ & $14(7.9 \%)$ & $15(8.4 \%)$ \\
\hline Morale in my ST3 practice was high. & $91(51.1 \%)$ & $38(21.3 \%)$ & $34(19.1 \%)$ & $15(8.4 \%)$ \\
\hline \multirow{2}{*}{$\begin{array}{l}\text { My morale has increased positively during } \\
\text { my ST3 year. }\end{array}$} & $86(48.3 \%)$ & $38(21.3 \%)$ & $39(21.9 \%)$ & $15(8.4 \%)$ \\
\hline & Yes & & No & Not answered \\
\hline \multirow{2}{*}{$\begin{array}{l}\text { Have you experienced any work-life } \\
\text { balance problems during ST3 training? }\end{array}$} & $97(54.5 \%)$ & - & $68(38.2 \%)$ & $13(7.3 \%)$ \\
\hline & Yes, in a positive way & Neutral & $\begin{array}{l}\text { Yes, in a negative } \\
\text { way }\end{array}$ & Not answered \\
\hline $\begin{array}{l}\text { The morale within my ST3 training practice } \\
\text { has influenced my future career intentions. }\end{array}$ & $91(51.4 \%)$ & $35(19.8 \%)$ & $34(19.2 \%)$ & 17 (9.6\%) \\
\hline $\begin{array}{l}\text { The current political and media comments } \\
\text { about general practice have influenced my } \\
\text { future career intentions. }\end{array}$ & $13(7.3 \%)$ & $58(32.7 \%)$ & $92(52.0 \%)$ & $14(7.9 \%)$ \\
\hline
\end{tabular}

*Participants only answered one of these questions: 93 participants reported having a GP placement during F2 and answered the question about its influence, while 74 participants reported not having a GP placement during F2 and answered the question about whether they would have liked one.

GP, general practitioner; F2, second year of foundation programme undertaken by all UK medical graduates; ST3, third year of specialist vocational training in general practice.

and patient care as they did and I felt general practice was the career to facilitate this. " $\mathrm{F}, 1,7$

Negative experiences, poor exposure and disparaging attitudes to general practice during undergraduate training had influenced consideration of specialist training choices.

"The statistic that $50 \%$ of students go into GP was used almost as a derogatory threat as though it was a second class career. One lecturer used the phrase 'those who can do medicine, those who can't do general practice'. ' F,1,3
"Though the medical school clinical rotation in General Practice was nominally the same length as other specialties, less than $40 \%$ of the time was spent within a practice; more was classroom-based. Despite coming to medical school with the intention of pursuing GP, the emphasis on acute specialties initially drove me to explore Emergency Medicine." $\mathrm{M}, 2,4$

There was an association between participants' rating of how well their specialist training had prepared them for a career in general practice and intended career plans for the next 3 years. Those who felt well prepared were 
more likely to plan to become partners $(28.0 \%$ compared with $12.5 \%$ who did not feel well prepared), whereas those who felt ill-prepared were more likely to anticipate becoming locums $(37.5 \%$ compared with $10.0 \%$ those who felt well prepared; $\left.\chi^{2}=10.17, p=0.04\right)$. In terms of 5-year intentions, those who felt their general practice training had prepared them well were more likely to aspire to becoming a GP partner (59.8\% compared with $7.7 \%$ of those who responded neutrally), whereas those who responded neutrally about how well prepared they felt were more likely to anticipate being a salaried GP in 5years $(84.6 \%$ compared with $38.1 \%$ who were well prepared; $\left.\chi^{2}=13.61, \mathrm{p}=0.009\right)$.

The experience of workload and support in training practices also affected respondents' career plans.

“...My first 6 months at practice was non-stop. Excessive home visits, admin and extras with scheduled teaching only held between sessions_made completing the workload, whilst revising for exams and completing practice based assessments, impossible. The difference coming into my second practice has been wonderful..... Had I not changed I would have probably left the training programme." M,1,15

\section{Workload and work-life balance}

Over half $(\mathrm{n}=97 ; 54.5 \%)$ of participants reported having experienced work-life balance problems during ST3 training and the majority of respondents agreed or strongly agreed that the workload in their ST3 practice has influenced their career intentions (see table 2). Those who experienced work-life balance problems were more likely to agree that their experience of practice workload was influencing career plans $(\mathrm{r}=0.213, \mathrm{p}=0.006)$ with $27.1 \%$ of those experiencing problems expecting to have left NHS GP within 5 years compared with $9.8 \%$ those not experiencing work-life balance problems $\left(\chi^{2}=\right.$ 6.62, $\mathrm{p}=0.01$ ).

Experience of heavy practice workload discouraged respondents from considering applying for partnerships, and instead encouraged respondents to seek the flexibility of locums or salaried positions, part-time work and employment opportunities that were outside standard clinical sessions, such as teaching, developing special interests and gaining diplomas, CCG work and out of hours services.

"The busy workload has put me off from partnership. That's why I want to do locums, be flexible. "F,1,16

"The partners often work till 8-9pm + do weekends due to extended hours etc. Have a young family and so would not consider partnership. " $\mathrm{F}, 1,3$

Portfolio careers were viewed favourably by many as they were described as offering flexibility, choice of working hours, ability to shape careers and protection from professional burn out.

"I'd like regular sports medicine clinics mixed with primary care clinics and events medicine and opportunities to expand and create extra earnings. I want time for creative thinking and being able to mould my career to where I want it to be." M,1,6

"I appreciate that working 8-10 clinical sessions per week wouldn't be sustainable; it is my hope that as my career progresses I will be able to become involved in education, pursue a specialist interest and potentially commissioning. I think this variety would allow a sustainablebalance. "M,1,12

"The future of general practice is portrayed as involving more work with less pay and so I intend to look to be a portfolio GP so that I have a balance between direct patient care and indirect patient care (eg, medical education, GP training) and can give more to my patients when having direct clinical contact but have job satisfaction and less stress as a result of engaging in alternatives to morning and afternoon surgeries. " F,1,7

"Working nine sessions leaves you emotionally and mentally exhausted by the end of the week. I think a portfolio career is the only way to achieve satisfaction of not leaving medicine altogether." $M, 1,15$

The perceived impact of general practice on worklife balance was driving some respondents to consider changing career altogether or looking to moving abroad.

"Change specialty to Paediatrics in September. I think as a salaried/partner there will be even more admin responsibilities and lots more dumping of work on general practice. I think stress levels will rise and I would rather do a job where I feel happy to go into work and where I don't have to worry about timing so much and battling patients. " F,1,22

"Plan to emigrate. Workload too high, not valued — have only just gained CCT and already considering other careers-not a good indictment of General Practice - the 'enjoyment' has gone, low morale, low respect, pay freezes, high complaints, high risk, high defence fees... " M,1,23

The option to work less than full time was suggested as a way to achieve a more positive work-life balance.

"Currently working $60 \%$ after returning from maternity leave. I have no plans to return to full time because of the pattern I have seen in GP where it generally seems to be thought of as silly to work full time due to the unsustainable workload." F,1,19

"Work 4-6 sessions long term. To facilitate work-life balance, managing stress levels through this respite to prevent burn out and maintain patient empathy. "F,1,30

\section{Practice morale}

Practice morale in their final year (ST3) of training had been a positive influence on career plans for 91 (56.9\%) respondents, but it had been experienced negatively by $24(21.3 \%)$ individuals. There were correlations observed between high ST3 practice morale and improvement in respondent morale $(\mathrm{r}=0.684, \mathrm{p}<0.001)$; and high practice morale and its influence on respondents' career intentions $(r=0.735 ; \mathrm{p}<0.001)$. Experiencing work-life balance 
problems was negatively correlated with personal morale $(\mathrm{r}=-0.242, \mathrm{p}=0.002)$.

"Having seen a fantastic example of an excellent partnership, I now realise that this may be something I want in my future. "F,2,23

"I have seen how hard GP partners work, but also that the work can be rewarding and there is a financial advantage over salaried work. Salaried GPs may have less 'additional work' but work can get 'dumped' on to them, and they less involvement in team decisions." M,1,25

"Struggled with home life due to long days at work, particularly when my half days finished late due to home visits and CSA revision plus trying to maintain the e-portfolio. "F,1,68

\section{Media and political commentary}

More than half ( $\mathrm{n}=92 ; 56.4 \%)$ felt that the current political and media comment about general practice was having a negative influence on their career intentions. Those who were negatively affected by the media's portrayal of general practice were more likely to report their morale as low $(r=0.291, p<0.001)$, and this was exacerbating their disillusionment with general practice as a career.

"I have found myself recently when driving home from more challenging days considering leaving general practice when I CCT. These are usually days when I feel I have been trying to solve problems that are probably not really in the GP remit. I think the media coverage increases these feelings. " F,U,26

"Media bashing of GP's has affected morale combined with poor training on how to actually run a practice this has led to fear of applying for partnerships. Salaried doctors are used and abused by Practices with no personal autonomy. Locum is the other option or emigrate. The tiered status within the profession needs to end." $\mathrm{F}, 1,5$

Negativity surrounding general practice was influencing respondents' career plans, particularly in relation to plans to become a GP partner.

"I no longer plan to try to go directly into a partnership, which was always my intention. Both the morale in my current practice and the in-fighting between partners, plus the soul destroying media coverage has made me put the brakes on this. I plan on looking for a salaried post initially and biding my time to see what happens in general practice over the next few years. " $\mathrm{F}, \mathrm{U}, 18$

"Constant GP bashing in media is demoralising, quite rare to hear stories about hard work and positive outcomes from primary care. Previously would have considered partnership but no longer, might consider locum or part time." F,1,20

Some also felt that the negative media influenced patients' opinions and expectations of general practice, contributing to unsustainable demands being placed on the profession.

"Concerned about the future of the general practice in terms of patient expectation and increasing workload without funding/solutions to effectively manage this-will be expected to do more and more and already very pushed. Burnout is likely." $\mathrm{U}, \mathrm{U}, 24$

"There seems to be bad publicity about general practice from every angle. If you look in a newspaper you are told about 'bungling GP's. The government seems to think that we are not working at all and all crisis in hospital is due to our lack of work......It all has led to a very negative atmosphere and makes me reluctant to go to work in the morning because I wonder what battle I am going to have to face that day." $\mathrm{F}, 1,22$

\section{DISCUSSION}

\section{Principal findings}

This study has highlighted a range of factors that appear to influence, often adversely, the career plans of newly trained GPs. Many of these relate to how general practice had been experienced across undergraduate, foundation and vocational training, and in particular perceptions about workload pressure and morale within practice placements. The negative portrayal of general practice by politicians and the media was experienced as having had a detrimental effect on personal career intentions. Sociodemographic factors, such as age, gender and having children, also influenced career plans indicating a need for these to be considered within workforce planning.

About a third of participants described an intention to be working outside NHS general practice. At 6 months post-completion of training, $62.8 \%$ expected to be working in the NHS in a salaried, locum or other non-principal GP role, reducing to $33.9 \%$ at 5 years, while $4 \%$ increasing to $33.9 \%$ expected to be working as GP principals at these points in time. Many were interested in developing portfolio careers, with less than full-time working in general practice. Of the remainder, some were planning to leave general practice completely, work overseas, take a career break/maternity leave or did not state a career intention. Personal experience of a poor work-life balance as a trainee was associated with intentions and particularly a lower expectation to become a GP partner.

\section{Strengths and limitations}

This study's findings reflect the views of a large number of trainees, with varied backgrounds and experiences of general practice training, all of whom were near completion of vocational training. Through a mix of open and closed questions it identified ambivalence about the current state of general practice in England, with factors influencing career plans including experience of undergraduate, foundation year and vocational training, practice workload, work-life balance, practice morale and media and political commentary.

However, it was limited to a single English region, which may limit the generalisability of findings to other areas. The response rate was reasonable for a self-completed questionnaire; those for whom sociodemographic data were known were representative of the cohort in terms of age and sex, but participants from ethnic minority 
backgrounds were under-represented. Questions varied in the extent to which they were answered by all participants, with some having response rates that were up to 9.6\% lower. A substantial proportion of this is accounted for by the nine participants $(5.1 \%)$ who failed to complete the survey (answered less than five questions). Inspection of the raw data did not reveal any pattern to the remaining missing data; respondents generally omitted individual questions rather than missing complete pages or stopping before the end of the survey. Hence, it is unclear whether this was done intentionally or not. In addition, the lack of demographic data provided by many of the participants limited the extent to which statistical analyses could be undertaken.

The inclusion of free text comments added depth to the quantitative data and so allowed a more insightful understanding of participants' views. However, it is recognised that these comments were limited to the issues covered in the questionnaire, and that individuals vary in the extent to which they are inclined to contribute comments, reflecting issues such as lack of time and interest. Those who feel more critical or strongly about a topic are more likely to comment, ${ }^{16}$ and this may have contributed to the overall negative balance reflected in the qualitative data. Semistructured interviews would have allowed deeper probing and may have led to the emergence of additional themes and subthemes, for example, with regard to promoting positive trainee experiences.

\section{Comparison with existing literature}

This study complements findings from other recent studies that have described the attitudes to general practice as a career choice at medical student, foundation and trainee level, and again highlights that heavy workload, low morale and negative perceptions of general practice are key factors influencing career plans. ${ }^{9-11} 14$ These factors are also reflected in established GPs who have similar plans to retire early, reduce hours of working, take a career break or emigrate. ${ }^{1-617}$

Our study adds an increased level of detail to understanding trainees' future plans with a clear drive away from partnerships towards salaried roles and from fulltime to part-time working in both men and women. Trainees express a desire to develop portfolio careers to add interest and improve work-life balance.

\section{Implications for future research and clinical practice}

The importance of addressing workload pressures, low morale and improving work-life balance in general practice is emphasised by the findings of this study, echoing a recent British Medical Association (BMA) survey finding that practices with higher workload are less successful in recruiting doctors. ${ }^{18}$ Recent reports and policy statements have indicated ways in which this might be achieved. The Roland report ${ }^{19}$ has argued the importance of widening skill mix in general practice, with workload that does not necessarily require a GP being delegated to other members of the primary care team to help ease pressures.
Additionally, the BMA has proposed locality hubs as a method of controlling the workload and aiding clinical capacity. ${ }^{20}$ However, such developments are unlikely to affect GP trainee experiences in the short term.

NHS England has recognised the need to identify measures to encourage GPs to enter and remain within practice, suggesting initial options such as funded mentorship scheme, opportunities to develop a portfolio career and a clearer range of career pathways. ${ }^{21}$ Our study supports this approach with many of the respondents proposing that they intended to seek additional portfolio elements to their standard clinical sessions or locum to achieve a sustainable work-life balance. Recognising and supporting the career intentions of GP trainees to develop portfolio careers may be a beneficial approach to helping trainees develop sustainable careers. Workforce planning will also need to account for the increasing number of GPs who do not wish to work full time in general practice.

Increasing exposure to general practice within undergraduate curricula is known to increase interest in general practice as a career choice, ${ }^{22}$ and our study re-enforces the importance that placements, both at undergraduate and vocational training levels, take place in environments in which there are positive role models who are enthusiastic about general practice. Demoralised practitioners who are feeling overwhelmed by workload are unlikely to enthuse students and trainees towards a career in general practice. Expansion of the foundation programme to increase the number of trainees who experience a training post in general practice could benefit recruitment, but close monitoring of training practices and the delivery of teaching is necessary to ensure training occurs within environments that have manageable workload, encourage trainees' professional ambitions and endeavour to maintain a high-morale workforce. Vocational training schemes should reflect the ambitions of GP trainees to develop portfolio careers by supporting them to experience and encouraging them to develop additional roles, whether clinical, academic or leadership. Innovative additional time training schemes are in place across the UK; these should be carefully evaluated and considered for further expansion.

\section{CONCLUSION}

It is essential for the future of general practice that medical students and doctors are attracted to undertake vocational training to become GPs, and that the experience of training encourages enthusiastic progression towards joining the GP workforce. This study highlights the importance that placements in undergraduate and vocational training practices are well supported, that training programmes encourage interest in developing portfolio careers and that the increasing workload and decreasing morale in UK general practice are combated to improve recruitment. 
Acknowledgements We thank the doctors who completed the survey and are grateful to the Health Education England West Midlands (HEWM) vocational training course organisers who assisted with encouraging trainees to participate. We are also grateful to Richard Singleton and James Gill who, as GP registrars, contributed to the design and distribution of the questionnaire.

Contributors JD and $\mathrm{KO}$ were responsible for the original concept of the study. $\mathrm{JD}, \mathrm{KO}$ and $\mathrm{RR}$ designed the questionnaire. RR led the qualitative analysis and ES the quantitative analysis, with input from KO and JD. All authors meet the ICMJE criteria: have made substantial contributions to the conception or design of the work; or the acquisition, analysis or interpretation of data for the work; drafting the work or revising it critically for important intellectual content; gave final approval of the version to be published; agreed to be accountable for all aspects of the work in ensuring that questions related to the accuracy or integrity if any part of the work are appropriately investigated and resolved.

Funding This research was funded by Health Education West Midlands (HEWM). The views expressed are those of the authors and not necessarily those of the funders; the latter had no direct involvement in the design and conduct of the study, the collection, management, analysis and interpretation of the data or in the preparation, review or approval of the manuscript.

Competing interests None declared.

Ethics approval University of Warwick Biomedical Research Ethics Committee.

Provenance and peer review Not commissioned; externally peer reviewed.

Data sharing statement № unpublished data are available for sharing.

Open Access This is an Open Access article distributed in accordance with the Creative Commons Attribution Non Commercial (CC BY-NC 4.0) license, which permits others to distribute, remix, adapt, build upon this work non-commercially, and license their derivative works on different terms, provided the original work is properly cited and the use is non-commercial. See: http://creativecommons.org/ licenses/by-nc/4.0/

(c) Article author(s) (or their employer(s) unless otherwise stated in the text of the article) 2017. All rights reserved. No commercial use is permitted unless otherwise expressly granted.

\section{REFERENCES}

1. Hann M, McDonald J, Checkland K, et al. Seventh national GP worklife survey. 2013. http://www.population-health.manchester.ac.u $\mathrm{k} /$ healtheconomics/research/reports/FinalReportofthe7thNationalGP WorklifeSurvey.pdf

2. Rosenthal J, Chana N. Future-proofing primary health care: gp recruitment and retention in the new NHS. Br J Gen Pract 2011;61:430-1.

3. Lambert TW, Evans J, Goldacre MJ. Recruitment of UK-trained doctors into general practice: findings from national cohort studies. Br J Gen Pract 2002;52:3649-72.

4. Drake D. How being a Doctor became the most miserable Profession The Daily beast: the Daily beast company LLC. 2014. http://www. thedailybeast.com/articles/2014/04/14/how-being-a-doctor-becamethe-most-miserable-profession.html (accessed 17 Mar 2017).

5. Fraser $\mathrm{A}$, Thomas $\mathrm{H}$, Deighan $\mathrm{M}$, et al. Directions for Change: a National Survey of General Practice training in the United Kingdom. Education for Primary Care 2007;18:22-34.

6. Hobbs FDR, Bankhead C, Mukhtar T, et al. Clinical workload in UK primary care: a retrospective analysis of 100 million consultations in England, 2007-14. The Lancet 2016;387:2323-30.

7. Taskforce GP. Securing the Future GP Workforce: Delivering the Mandate on GP Expansion. GP Taskforce Final Report. Leeds: Health Education England. 2014.

8. GP National Recruitment Office. Recruitment Figures. 2016. https:// gprecruitment.hee.nhs.uk/Portals/8/Documents/Annual\%20Reports/ GP\%20ST1\%20Recruitment\%20Figures\%202016.pdf

9. Lambert TW, Smith F, Goldacre MJ. Trends in attractiveness of general practice as a career: surveys of views of UK-trained doctors. Br J Gen Pract 2017;67:e238-e247.

10. Merrett $\mathrm{A}$, Jones $\mathrm{D}$, Sein $\mathrm{K}$, et al. Attitudes of newly qualified doctors towards a career in general practice. Br J Gen Pract 2017;65:e253-9.

11. Marchand C, Peckham S. Addressing the crisis of GP recruitment and retention: a systematic review. Br J Gen Pract 2017;67:e227-e237.

12. Watson J, Humphrey A, Peters-Klimm F, et al. Motivation and satisfaction in GP training: a UK cross-sectional survey. $\mathrm{Br} J$ Gen Pract 2011;61:645-9.

13. Wordsworth $S$, Skåtun $D$, Scott $A$, et al. Preferences for general practice jobs: a survey of principals and sessional GPs. Br J Gen Pract 2004;54:740-6.

14. Mazhar K, Rashid A. What are the career plans of GP trainees and newly qualified general practitioners in the UK? A national online survey. J Gen Pract 2016;04:2.

15. Gale NK, Heath G, Cameron E, et al. Using the framework method for the analysis of qualitative data in multi-disciplinary health research. BMC Med Res Methodol 2013;13:117.

16. Garcia J, Evans J, Reshaw M. Is there anything else you would like to tell us - methodological Issues in the Use of free-text comments from postal surveys. Qual Quant 2004;38:113-25.

17. Dale J, Potter R, Owen $\mathrm{K}$, et al. Retaining the general practitioner workforce in England: what matters to GPs? A cross-sectional study. BMC Fam Pract 2015;16:140.

18. BMA. Safe working in General Practice. 2016. https://www.bma.org. uk/collective-voice/committees/general-practitioners-committee/ gpc-current-issues/locality-hub-model (accessed 17 Mar 2017).

19. Primary Care Workforce Commission. The future of primary care: creating teams for tomorrow. Health Education England. 2015. https://hee.nhs.uk/sites/default/files/documents/The\%20Future\% 20of\%20Primary\%20Care\%20report.pdf

20. British Medical Association. National survey of GPs. the future of general practice 2015. London: BMA , 2015.

21. England NHS. Building the workforce-the new deal for genera practice. 2015. http://www.england.nhs.uk/commissioning/wpcontent/uploads/sites/12/2015/01/building-the-workforce-new-dealgp.pdf (accessed 17 Mar 2017).

22. Alberti $H$, Randles HL, Harding $A$, et al. Exposure of undergraduates to authentic GP teaching and subsequent entry to GP training. $\mathrm{Br} \mathrm{J}$ Gen Pract 2017;65:e248-52. 